\title{
De la ciudad dictatorial a la resistencia del silencio: escrituras de Elvira Hernández y Liliana Lukin*
}

From the dictatorial city to silence resistance: writings of Elvira

Hernández and Liliana Lukin

\section{Fernanda Moraga-García}

Universidad Católica Silva Henríquez

Moraga.fer@gmail.com

El artículo explora dos textos. Uno es el libro inédito Pena corporal de la poeta chilena Elvira Hernández y que fue escrito entre 1983 y 1987 y el otro es el libro Descomposición (1986) de la argentina Liliana Lukin y que se contextualiza entre 1980 y 1982 . En (1986) de la argentina Lillá ambos se intenta indagar de que manera es (fue) posible la representación de la violencia extrema e institucionalizada por las últimas dictaduras. El eje de lectura está focalizado, preferentemente, en las construcciones simbólicas de la ciudad y el siléncio

Palabras clave: Poesía de mujeres, cono sur, ciudad, memoria, silencio.

The article explores two texts: the unpublished book Pena corporal by Chilean poet Elvira Hernández, written between 1983 and 1987, and Descomposición (1986) by Argentinian Liliana Lukin, set between 1980 and 1982. Both works attempt to investigate how it is (was) possible to represent the extreme violence that was institutionalized by past dictatorships. The reading focus is set, preferably, on the symbolic construc tions of the city and silence as discursive strategies for constructing meaning, in both resistance and imposition.

Keywords: women's poetry, Southern Cone, city, memoir, silence. 


\section{Salvaguardando la memoria}

Los golpes militares en el lado sur del continente dejan al sujeto de nuestra historia local en un desolador estado de catástrofe. Una vez arrasados los proyectos democráticos, las dictaduras reorganizan duramente el tejido de categorías y símbolos, es decir, desmantelan la construcción cultural de las representaciones para ordenar la sociedad bajo sus lógicas autocráticas de dominio. No se puede negar que las diferentes disciplinas militares de seguridad nacional -y su delirio por el orden y la homogeneidad-instauran un intocable "sistema de representación" en el que las dictaduras fundamentan sus interdicciones y castigos. Entonces, si bien la violencia de los golpes militares "des-encaja" la representación histórica, la recién llegada estructura representacional de la cultura militar se hace cargo muy pronto de reenmarcar a la sociedad dentro de la distribución dicotómica del orden y el caos para proscribir toda "salida de marco" que pudiera llamar implícita o explícitamente a la indisciplina. Los regímenes militares instituyen una ya sabida cultura del miedo que empapa todo el paño comunitario, forzando a los cuerpos y a la ciudad que habitan a encauzarse por la anulación, la exclusión, la persecución y el castigo; siendo la política y lo político las categorías o dimensiones sociales y culturales más duramente patrulladas y condenadas (Richard, 2011). Asimismo, las dictaduras de este sur de América lograron que el encarcelamiento arbitrario, la tortura sofisticada, las desapariciones forzadas de personas, el exilio y el insilio hayan sido un referente social, político y estético ineludible durante todos estos años, hasta hoy. Una de las piezas trágicamente específicas de esta región es la sofistificación del sistema opresor, el que consiguió con perversa eficacia que "el horror pasara como si no pasara nada" como bien lo han dicho antes. La institucionalización de la tortura fue un elemento clave del poder, el vértice más infame de su lógica de mandato que, incapaz de generar la participación y la aprobación, impulsó el sometimiento, la insurrección, la fuga o la resistencia. Dentro de una esfera opresiva, Michel de Certeau afirma que se sustituye la diversidad conflictual de una sociedad viva por una dicotomía totalizante. La impostura de ley del Estado totalitario se brinda como ineluctable y sin fallas, proponiendo un discurso de contrarios absolutos que arbitran el bien y el mal y se separa socialmente lo limpio de lo sucio" (De Certeau, 1987 citado en Viñar, 1993:112).

Bajo tales circunstancias, la cultura y el arte (entre ellos la literatura y la poesía) se convierten en espacios que posibilitan la conducción de lenguajes y significaciones indirectas, elusivas, fragmentadas y experimentales de lo censurado o invisibilizado por el discurso oficial.

Escribir literatura durante e inmediatamente después de las dictaduras, tanto en Chile (1973-1990) como en Argentina (1976-1983), tuvo como objetivo fundamental resignificar y reconstruir sentidos ante el silenciamiento impuesto sobre la memoria colectiva, proponiendo discursos que se posicionaron en el cómo representar la terrible historia que se vivenciaba. En particular, las poetas que escriben bajo dictadura en ambos países $-y$ que siguen escribiendo hasta hoy- asumieron una responsabilidad con la memoria social, política y de género. Es indudable, en este sentido, que bajo contextos de represión las representaciones poéticas de los sentidos 
históricos y culturales de estas dimensiones de la experiencia se complejizan tanto en el uso del lenguaje, como en su contenido. Esta forma de "poetizar" trae consigo una urgencia respecto de salvaguardar retazos particulares de memorias, las que incluso, una vez que concluyen las dictaduras, se convierten en portadoras de representaciones de silencios voluntarios como de aquellos que se han querido imponer hasta ahora, bajo diferentes dispositivos de silenciamiento que se inician con los ya conocidos discursos de "reconciliación nacional".

Aunque en este artículo no se alcanza a profundizar acerca de las tensiones y conflictos de poder que intervienen en la producción de la memoria, pensamos que es fundamental señalar, por lo menos, que el explorar los sentidos de la memoria en representaciones - poéticas- de experiencias $y$ sentidos de la memoria en representaciones - poéticas- de experiencias y
sujetos que han sido vulnerados por las relaciones de poder dentro del marco de las dictaduras en el Cono Sur, significa, entre otras cosas, pensar la violencia organizada que ha estado presente en dichas relaciones de poder ${ }^{1}$. Esto apunta a la comprensión del proceso de construcción de la memoria como práctica de dotación de sentidos, no solo de la realidad inmediata en que se sitúan los últimos regímenes de terror en el Cono Sur, sino que en su articulación cultural, histórica y política con un presente próximo y con la imaginación del futuro. Considerando esta dimensión en la reflexión, los sentidos de la memoria aparecen conformando un espacio dialógico -no ajeno a contradicciones y conflictos-, debido a que se configura como un tejido interconectado de contextos de impunidad, violencia y silenciamiento, y a partir de los cuales emergen, en filigrana, relatos de simbolización de despojos y deshumanizaciones que han cosificado a los sujetos y sus cuerpos. Con esto nos referimos especialmente a lo que Jelin llama los trabajos de la memoria (2002):

¿Por qué hablar de trabajos de la memoria? El trabajo como rasgo distintivo de la condición humana pone a la persona y a la sociedad en un lugar activo y productivo. Uno es agente de transformación, y en el proceso se transforma a sí mismo y al mundo. La actividad agrega valor Referirse entonces a que la memoria implica "trabajos" es incorporarla al quehacer que genera y transforma el mundo social (Jelin, 2002:14).

De este modo, trabajar por la memoria es indagar en los sentidos que la construyen y seguir las huellas, los retazos, los recortes y los silencios que van enfatizando esos sentidos, es decir, es la voluntad de ejercer una acción que requiere un esfuerzo por aportar lecturas y transformaciones que renuevan significados y proveen de contenidos al proceso de las memorias. Es por esto que pensamos que la producción poética de mujeres durante las las memorias críticas de desconstrucción y construcción. Asimismo, este

1 Existen marcos históricos y políticos específicos que en América Latina producen tensiones de poder y que van tejiendo la memoria latinoamericana. Nos referimos a la imposición de sistemas hegemónicos como las dictaduras, el neoliberalismo y las llamadas transiciones a la democracia, por ejemplo. 
campo cultural funciona como una narrativa de la memoria en el sentido que lo plantea Jelin (2002), puesto que es un vasto y heterogéneo instrumento de configuración de sentidos de la memoria, por cuanto se posiciona como una construcción cultural-social comunicable a otros dentro de los mismos marcos de represión o posterior a ellos. Son textos que proporcionan al sujeto que lee la posibilidad reflexiva de volver sobre sí mismo, sobre el pasado -su pasado o el de otros-, sobre estados límites y traumáticos en correlato con la militarización de la vida cotidiana, con los rastros del dolor, del miedo y la sospecha concentrados en la memoria corporal de la experiencia. Esto señala un necesario ejercicio político, afectivo y ético. Inclusive, dicho proceso es susceptible de ofrecer comprensiones generales $y$, sobre todo, particulares del pasado. Igualmente permite explorar los significados construidos en relación con las posibilidades del sujeto, sus fugas, insubordinaciones y resistencias.

Una de las tensiones que aparecen en la literatura de fin de siglo XX que se inmiscuye en momentos históricos de violencia, es la frontera entre el testimonio (presentación y descripción) y la ficcionalización (representación). En y tras la experiencia dictatorial, la poesía busca responder a esa tensión, pero vacila frente a la posibilidad de "nombrar" el terror, por lo que acude a diferentes formas de representación estética en las que se ve fundamentalmente involucrado el lenguaje y sus diversas dislocaciones en sus estrategias del decir los sentidos del horror y su repercusión en la experiencia, los cuerpos y los espacios, tal como señalan Jelin y Longoni "la violencia puede ser tratada en arte tanto desde la alegoría (o la representación) como desde la literalidad (o la presentación) (2005). Así, la poesía contribuye a la memoria en la medida en que esgrime el poder de la interpretación del mismo modo en que lo hace un lector o lectora activa. De esta forma, las dictaduras, al desarticular el lenguaje y por lo mismo, la producción literaria, hacen emerger, por oposición y resistencia, una proliferación de discursos poéticos que no se someten a los preceptos tradicionales de sus pares poetas anteriores y mucho menos, a los de signo hegemónico, sino que se fundan en la exploración de los desestabilizados codigos de las subjetividades mancilladas, de los cuerpos violentados y las identidades quebradas, mediante juegos y complejidades lingüísticas de denuncia y resistencia.

El corpus poético de mujeres que escriben bajo estas dictaduras en el Cono Sur instalo, entre otras cosas, la incertidumbre sobre la posibilidad de ordenar discursivamente los escabrosos sentidos de la realidad, abriendo así la interrogante: ¿cómo se puede representar o decir la violencia y el caos contextual que se vivía, pensando que la producción poética y literaria no se hace $\sin -y$ menos fuera de- las significaciones de la historia? En respuesta, las poetas que escriben en los 80 empiezan a objetarse y a resistir la historia impuesta a partir de una apuesta escritural que manifiesta un alcance entre propuesta crítica -la que se traduce, muchas veces, en un efecto político de construcción de memorias recientes- y propuesta poética o modos de representaciones de las consecuencias del terrorismo de Estado. En este último sentido, esta poética se propone una narrativa o mejor dicho una desnarrativa no conciliatoria del presente de la época. Nos parece que este campo poético de mujeres conosureñas, junto a otras apuestas poéticas de sus pares varones, pueden situarse en torno a una subversión en cuanto 
se construyen como "antidiscursos", ya que promueven ciertas hablas de autoproducción de subjetividades que operan fugas en las restricciones o silencios impuestos a la identidad. En este caso, estos "antidiscursos" señalan construcciones políticas de la subjetividad que no solo apelan a identidades perdidas, censuradas, ausentes, fragmentadas o degradadas, sino que también y, sobre todo, a dimensiones más íntimas de la identidad. Esta subversión de la subjetividad y la identidad tiene como resultado o se relaciona con la percepción de que la polisemia, la agramaticalidad, las rupturas de las expectativas convencionales de la retórica y que emergen en la escritura poética que ahora revisamos, organizan una forma verbal análoga a las complejidades de una subjetividad que se construye a partir de una propia comprensión de sí misma y del entorno (Dalmaroni, 2004).

De aquí entonces, que nos interesa aproximarnos a la escritura poética de mujeres de la región que, de algún u otro modo, sorteando censuras, persecuciones, invisibilidades, exclusiones, prisiones e incluso torturas lograron hacer circular sus libros, ya sea por canales alternativos al oficial o con publicaciones posteriores a la escritura real de ellos, debido a las circunstancias de vigilancia y opresión que se vivían. Por ahora, nos concentramos en la lectura de dos producciones poéticas de mujeres en pleno periodo de dictaduras. Por una parte, revisamos el texto inédito Pena corporal de la poeta chilena Elvira Hernández y por otra, el libro Descomposición de la argentina Liliana Lukin. En ambos se intenta explorar de qué manera es (fue) posible la textualización poética o la representación de contextos de violencia extrema e institucionalizada. El eje de lectura está focalizado preferentemente, en las construcciones simbólicas de la ciudad y el silencio como estrategias discursivas de sentido, tanto de resistencia como de imposición.

\section{La ciudad tiene una pena yendo y viniendo por un infamado país}

El libro inédito de Elvira Hernández, Pena corporal, fue escrito entre 1983 y 1987, período aún severo del dominio militar en Chile. Si intentamos indagar en la problemática de la representación de la violencia, nos encontramos con que la experiencia de un país en decadencia se lee, principalmente, por medio de la degradación del cuerpo y de una subjetividad urbana. Por lo mismo, el texto -en la construcción de su lenguaje- se despliega entre la desfiguración de un espacio y la insistencia del signo enmascarado en querer develar, hablar, denunciar, moviéndose permanentemente entre "el trozo y el destrozo" (Dalmaroni, 2004:136):

\section{Pintarrajeada}

Rajada

Empielada una y otra vez con tintes

Raspada

Desconchada

Sucia

Basureada

Llena de humos como una mujer burguesa

Me doy en arriendo

Por la noche me tapan los periódicos el cadáver 
Por la noche me ocupan los vagabundos

Me meten fierro

Se ocultan por mis cuatro costados

Abiertos mis forados son cueva de ratas (Hernández, 6) ${ }^{2}$.

De este modo, la primera impresión crítica que ha seleccionado la hablante de los poemas y que va configurando el bolo nutritivo de su contradiscurso, es que infringe la imagen de ciudad uniformada y saneada por la ordenanza marcial. Por lo que la imagen de ciudad vejada de Elvira Hernández, frente a la ciudad pacificada que ha impuesto el nuevo mandato castrense y que implica la conclusión de lo urbano (Sarlo, 2009:143), viene a levantarse como una desclasificación de esta suburbanidad convertida en basural de subjetividades. La clausura de lo urbano, en el sentido de un corte abrupto de los múltiples intercambios sociales, culturales y políticos, entre otros, conduce al desplazamiento o silenciamiento de los nudos inevitables que se dan dentro de los procesos de configuración social. La postulación de lo "perfecto" o del fanatismo de lo homogéneo implica la radical exclusión, en este caso aniquilación, castigo o expulsión del "otro" convertido en excrecencia. Si la ciudad "blanqueada" de la dictadura construye espacios inhabitables, la ciudad de Pena corporal señala que "la orina lava por su cuenta el vómito del piso" (15) y la "carga fecal sanguinolenta" (15), por lo tanto, la representación aquí evacuada corresponde a esos mismos espacios inhabitables, invivibles o decididamente, insoportables. El discurso poético en este sentido se concentra en la destrucción de la circulación urbana en todos sus sentidos y sinsentidos a partir de la pérdida de la convivencia. Sin ciudad, no hay tejido social, nos quiere decir veladamente la poeta, dejando al descubierto la barbarización que es consecuencia de la ausencia de límites.

Elvira Hernández propone una ciudad distópica como una periférica infernal, en la cual el recorrido de la sujeto también se hace infernal: "hoguera / tímpanos en estampida/ [...] / hierro candente para la piel que escrota" (15). La escritura apunta a las secuelas inmediatas de la brusca desaparición de una ciudad y la emergencia de otra, impuesta. Para representar estas secuelas, la voz enunciativa se posiciona en la pulsión inevitable de ciertas desviaciones que la misma oficialidad construye, pero oculta. En este sentido y sumado a lo que ya hemos comentado, la ciudad marginalizada y despedazada que nos presenta el poemario también se alimenta de otras ingestas del horror que van cebando la caída inminente del cuerpo y la subjetividad urbana y que a la vez, dan cuenta de una enmascarada contextualización de la época. Me refiero por una parte, al diálogo que la hablante mantiene con algunos sujetos no ficcionales, los que le dan sentido político de resistencia a la experiencia dañada, al mismo tiempo que se transforman en márgenes metafóricos de imputación respecto a torturas, desapariciones y al silencio que se ejercía sobre las acciones terroristas del Estado:

2 En las siguientes citas del texto de Elvira Hernández solo se mencionará el número de página. 
¡Qué hacer en tu nuez de mármol Andrés García! ${ }^{3}$

$[\ldots]$

iCuánto trabajo para la enfermería!

Mira esas carnes jugosas retorciéndose

Picaneadas azulosas en la parrilla (18).

O este otro:

Nadie podrá canonizar el cuerpo fulgurante

De Rodrigo Rojas Denegri ${ }^{4}$.

Querrán apagar el deslumbrón de su piel como ampolla

Una ampolleta de carne y kerosene

Su chispazo se perderá en el oscuro

Y el silencio clavará diez mil agujas

Y las manos se pondrán al fuego

Y milagrosamente caerá tierra sobre los ojos

Amén (16).

Este último fragmento pertenece al poema que abre, en el libro, la mención explícita a la dictadura, aludiendo al silencio como estructura de verdad. Este breve texto, en el que además se alude al cuerpo calcinado de Rodrigo Rojas, presenta cierta cercanía irónica con algún rezo cristiano, finalizando con la verificación de una elipsis, debido a que la voz enunciativa afirma el silencio impuesto frente a los crímenes y porque además, sabemos que sellar con la voz "Amén" es proclamar que se tiene por verdadero lo que se acaba de decir.

En una línea similar a estos desvíos de acusación y con un juego de analogías, en el poema "Posiciones indecentes" se consignan entre otros, los siguientes versos: "cuando los Pastores entregan las ovejas a los Perros para que las muerdan y corran [...] cuando los Pastores y los Perros comen en un mismo plato / Cuando los Pastores se convierten en Perros" (17), los que finalizan con varios puntos seguidos que llevan a pensar que las "posiciones indecentes" de los dictadores son infinitas en su propia indignidad y con los demás. Redundante sería la clarificación de las representaciones analógicas de los "Pastores", los "Perros" y las "ovejas" con relación al contexto, puesto que son abiertamente identificables. Por otra parte, también se despliegan otros virajes de la violencia y que se señalan a partir de lo que la experiencia de la sujeto se ve obligada a consumir. Se trata, por ejemplo, del nefasto encuentro de la sujeto con una modernización que es parte del proyecto neoliberal impulsado por la dictadura en los años 70 y 80 en Chile, y que tiene como resultado inmediato una rápida corrupción y desigualdad social.

3 Detenido desaparecido a los 29 años y encontrado en el Patio 29 el año 2013, mucho después de la escritura de este libro. Detenido junto a Jorge Muñoz (18 años) el 18 de septiembre de 1973. Ambos fueron calificados como víctimas de desaparición forzada por el Informe de Comisión de Verdad y Reconciliación.

4 En 1986, durante una jornada de protesta nacional en contra de la dictadura de Augusto Pinochet, una patrulla militar golpea y rocía con bencina los cuerpos de Carmen Gloria Quintana y Rodrigo Rojas Denegri, abandonándolos, luego, en un sitio eriazo. A causa de as quemaduras sufridas, Rodrigo Rojas fallece cuatro dias después. 
Bajo el mando de esta hegemonía económica, la que dio origen a lo que el conservadurismo de la época no se demoró en bautizar como el "Milagro de Chile"5, la ciudad de Elvira Hernández vuelve a construirse como el eje de esta dimensión de las arcadas del discurso:

abro el night club para ti

"La Dionea"6

Lo perfumo

Doy lustral a la corona labiada

$Y$ al estilo insoluto llama

Lo preparo a la dedada

$[\ldots]$

Te doy la bienvenida sarcástico

Preparo tu entrada

¿cuál de mis gestos crees que debes pagar? (7)

Sin duda, estamos ante la gran puta (y) madre: la ciudad del libre mercado. Se abre el espacio fundamental de la cosificación y mercantilización del cuerpo. La transacción de la carne por dinero, donde la vagina actúa como la puerta de entrada mayúscula y que, en el poema, es la simbólica de un lugar de acceso en el que se atrapan las moscas vivas ("La Dionea") que son atraídas por la basura que esparce a diestra y siniestra el proyecto económico ya mencionado y del cual Chile fue, y sigue siendo, uno de los estudiantes más entusiastas de América Latina. En relación con esto, la sujeto de los poemas nos dice con un tono mordaz: "Somos la descarnada raza del sur $/[\ldots]$ / Vertebrados que comen donde otros defecan /[...]/ iQué nunca nos exilien la sumisión! / ¿Qué seríamos? (14).

El imaginario urbano que la poeta nos propone corresponde a una ciudad ocupada o más bien pisada, pisoteada, no solo por el crimen y el terror, sino que también por las signos superficiales del progreso que engañan y escamotean las confianzas de quienes, en algún momento, imaginaron que el infortunio de la invasión española podía ser amortiguado por alguna justicia de orden republicana. Por lo tanto, el "quiasmo" (Brito, 1990) que se descarga en esta nueva y brutal invasión militar es la herida en el cuerpo de la ciudad, debido a la violenta adulteración de un orden. En este sentido, podemos pensar como lo pensaba Martínez Estrada (2003) para la construcción de la ciudad argentina y como lo señala Eugenia Brito (1990) respecto del contexto chileno en dictadura: la repetición del fracaso de la ciudad estaría dado o tendría su origen en la violación de América por una casta de conquistadores canallas, movidos por una ambición convertida en locura.

${ }^{5} \mathrm{El}$ término fue acuñado por Milton Friedman, líder del conservadurismo económico estadounidense. En Chile, los llamados "Chicago Boys" fueron sus discípulos y aplicaron, durante la dictadura, sus políticas del libre mercado, provocando una profunda desigualdad social. Por su parte, en Argentina los "Chicago Boys" también entraron en la escena económica de la mano con el golpe de Estado en 1976, teniendo similares consecuencias para la sociedad argentina.

6 Planta carnívora atrapamoscas, atrapa presas vivas. 
Hablamos entonces aquí de un primer canibalismo cultural. Un segundo canibalismo y tan explícito como el anterior, estaría dado en esta proyección del "quiasmo" en la instalación de la dictadura, no solo en Chile, sino que en toda la región. Se trata de una: "...mala cruza, este continuo presente del pasado en moldes nuevos [...], la barbarie que vuelve..." (Adrián Gorelik, 2004 citado en Sarlo, 2009:159). He aquí entonces el cuerpo degradado de la ciudad en Elvira Hernández. Espacial y subjetivamente, la ciudad de Pena corporal resulta de un embutido por superposición de fragmentos, por agregados, por metástasis que van configurando una sarnosa excrecencia. Es contrahecha y engorda, como un organismo contagioso, bajo la boca hambrienta de un animal corrupio y canibalesco que, a mascadas, destruye el mapa de las subjetividades urbanas: "allí amontonados en el vivario-vivir / reos XX-XY [...] /arrastrados de la boca, entusiastas / contagiados por el Sarcoptes Scabei / de la vida que nos ara" (1). Así, la ciudad es cárcel y enfermedad donde el "Yo" (con mayúscula, supremo) es "El Viejo perro lamiéndole pelos a su perrita / despegando crencha" (4), para acomodarle un fatídico lugar a la hablante de los poemas ("haciendo un lugar para mí", dice la sujeto). De esta forma, la poeta nos hace sentir en la ciudad el golpe de la historia, su herida ("Que no nos dejan dormir sus llagas", [1]), su incógnita ("sin otras letras que estas", [4]) y sus amenazas ("pirañas, pulpos, sapos, arañas-gamadas, S.S.-A.A"., [5]).

A partir de esta, aun inicial revisión del texto de Elvira Hernández, podemos decir que en él se reivindica el corte, el trozo y la interrupción para exaltar el salvaje quiebre de los códigos con que la dictadura alteró los espacios de sentido de la sociedad. La autora acude a la representación del margen como posición enunciativa y como recurso estratégico para significar el desencaje de subjetividades en conflicto de pertenencia y de representación y que se ubican en los costados de la exclusión social. Una de las propuestas, a nuestro juicio, relevantes que presenta el libro y que en la escritura de esos años en Chile es reconocible en varias autoras, es que se propone quebrantar la envoltura de una ciudad clausurada en el mandato de "orden y paz", denunciando marcas de miseria y degradación individual y social, de perturbación psíquica y agonía corporal, de humillación moral y aniquilamiento biográfico. Como lo expresa Naín Nómez cuando se refiere a la producción poética de los primeros años de dictadura, el poeta busca "bajo los escombros de un sujeto generalmente fragmentado, vacío, exiguo, marginado, dolorido" (2008:96) o como afirma Magda Sepúlveda en uno de sus estudios sobre ciudad y escritura de mujeres en dictadura: "se simbolizan así los tránsitos subterráneos y fragmentarios como modo de habitar durante la dictadura" (2008:6).

Con lo que se ha dicho hasta ahora parece importante destacar, primero que la construcción del poemario Pena carnal en un sentido de "antidiscurso", no lo es porque esté alejado del carácter hegemónico del discurso militar, sino que más bien, porque se acerca hasta malograrse, asumiendo o deglutiendo los elementos más feroces no solo por los que se construye el discurso del dictador, sino que también de su puesta en práctica. Segundo y como consecuencia del anterior, el acto de representación del terror se

7 Especie de ácaro, arador de la sarna. 
produce, precisamente, por medio de la metaforización de aquello que se obliga a la sujeto a experienciar, pero con la variante de que aquello que le fue obligado a vivir se convierte en el nutriente de su experiencia, sin duda infame, y de la que quiere dar cuenta mediante desvíos, pedazos, ironías, parodias, marginalidades y subjetividades rotas. Es así como la experiencia desgarrada del cuerpo y la subjetividad urbanas, son expuestas muchas veces sin apelar a las sutilezas del lenguaje con el fin de subrayar la degradación de un sujeto emplazado en una marginalidad que se corroe en los aspavientos de un progreso "in progress" para "empielar" la ciudad hasta las más altas cúspides de la superficialidad y a todas vistas, ultrajada y prostituida.

La polisemia del texto nos plantea que devorar al otro para lograr la acometida de transformarlo en tótem está lejos de sus propósitos, ya que más bien lo que se desea es escupirlo en su real perfil de monstruosidad para conseguir lo que es propio. Elvira Hernández genera una versión atrozmente digerida de lo censurado y violentado, ya que mediante la parodia, el sarcasmo, el filtro en la imagen, entre otras estrategias discursivas, se escribe la historia terrible del terrible enemigo.

\section{De la desaparición forzada a la ciudad ausente}

De igual forma que en la perspectiva de producción de memoria a la que nos referíamos en el primer apartado de este artículo, existen o pueden existir "vacíos" señalados, por ejemplo, en la ausencia de representaciones que no son precisamente pérdidas en sí mismas u olvidos. Me refiero aquí a la "ausencia" de un espacio exterior o urbano en el poemario Descomposición de la poeta argentina Liliana Lukin. Según lo que se indica bajo el nombre del libro, este habría sido escrito entre los años 1980 y 1982, hacia finales de la dictadura en Argentina y publicado en los primeros años de posdictadura: 1986. Antes de ocuparnos de lo anunciado respecto de la representación de una "ausencia" en el texto de Lukin, es necesario señalar que a partir del título del libro entramos a una exploración de lo descompuesto en varios sentidos. Por una parte, el propio libro se estructura como una "desorganización", puesto que se inicia con el prefacio y finaliza con el prólogo. Por otra parte, la autora nos presenta el deterioro y la corrupción del cuerpo y del lenguaje como consecuencia directa del contexto de terror. Igualmente, el texto nos entrega la alteración o desquiciamiento de un enfoque, fundamentalmente marcado por la desarticulación de la mirada, por un mirar que se disloca a partir de la violencia y que, sin embargo, resuelve representar un colectivo corporal que se hace y se dice por intermedio de los retazos de un lenguaje en descomposición ${ }^{8}$ :

estar colgado así:

no bella de mirar

no al aire piedra en el cuello

o cal tragada viva

8 Jorge Monteleone plantea al respecto que durante la dictadura el "desfase entre lo que podía ser dicho y lo que se hallaba oculto alteró toda la discursividad social y el régimen de lo visible en Argentina" en revista Milpalabras. 2003, número 5, p. 28. 
ligaduras en ristre / marcas / esa posición

$$
\text { fuera / de sí (Lukin, 1986: 6) } 9
$$

Asimismo, la descomposición abarca el espacio como un territorio apenas pronunciado y que se convierte en el límite asfixiante y reducido donde van desapareciendo los cuerpos: "cerrar esa ventana clausurar / la puerta la verja y el camino" (23). En este momento es que retornamos a lo que se había señalado al inicio de esta sección. La "ausencia" o el silencio en el libro de Liliana Lukin se presenta a lo menos de tres maneras: el silenciamiento como condición sine qua non de la política represora de los militares, el silencio como estrategia discursiva de la dislocación o descomposición de la mirada y el silencio como ausencia de representación. Estas dos últimas son las que más interesan en este momento, puesto que se derivan no del terreno de lo inexpresable -aquel que está más allá o más acá del lenguaje-, sino que se trata de la voluntad de supresión, por lo que se elabora como una elipsis que está en la misma construcción estratégica del lenguaje. Nos referimos al silencio del saber, es decir, aquel territorio que la poeta propone dentro de un marco descarnado de las políticas de desaparición forzada de personas como forma de ocultamiento de pruebas del genocidio. Es justamente en esa desaparición de subjetividades y cuerpos de la tortura que la voz enunciativa de los poemas altera su mirada, incluso hasta la ceguera porque a todas luces y por contradicción, la ausencia de los cuerpos define un espacio de conocimiento que no puede ser traído ni significado, nada más que, por un lado, con la muerte, la mudez debido a un lenguaje custodiado que apesta porque no se puede decir y por otro lado, con la memoria, pero aquella que apenas puede ver-recordar:

\section{una palabra}

si se guarda mucho tiempo

larga heces

materias hirientes

al ojo y al oído (9)

[...

ellos allí y nosotros

cosiéndonos los ojos (20)

el cuerpo mas cuerpo es el cuerpo muerto (14)

$[\cdots]$

una ventana / un ojo

estaca en la piedra

aguja / madera

cumpliendo su designio.

CLAVAR

para que callen

esas puertas esa temibles

9 En las restantes citas del libro de Liliana Lukin, solo se hará mención al número de página. 


\section{puertas}

cuyo párpado cerrado

es la manera de ver (11).

Emerge la ausencia de lo que no está representado porque se ha cercado el círculo de la vida en lo que ya se ha mencionado antes, en la desaparición y en la muerte, por lo que cualquier exterior desaparece. En este sentido, aparece la interrogante acerca del espacio urbano no como simbolización de una zona de circulación de sentidos y comunicaciones colectivas, sino que más bien como una posible dimensión de un estado de sitio, del cerco de los cuerpos violentados y que no está. El texto suprime la ciudad para llevarnos a comprenderla como aquel espacio físico y temporal que debiera traer las memorias y las experiencias de la infancia y de otro presente a modo de resguardo, pero que no existe porque ha sido violado:

desplazamiento del cuerpo el cuerpo el cuerpo

dejando en el asfalto dedos como piernas

inútiles banderas que nadie hará sonar" (7).

$[\ldots]$

un pasado para levantarse

desde la infancia

haría

falta

sacudido por el goce

de un mar aún no entrevisto

y el canto de sirenas

que lamía las calles (24).

La no representación evidente de la ciudad podría tratarse de rastros disimuladores que almacenan información sobre lo acontecido. Nos hace sentido entonces lo que Ricoeur (1999) señala cuando apela a que una omisión planea olvidos fundados en lo traumático, lo selectivo, supresiones que se configuran como espacios esquivos que finalmente funcionan como estrategias de evasión, de no saber o no ver en un marco de relaciones de poder. Sin embargo, y considerando que la ausencia de construcción urbana en Descomposición podría construirse desde la perspectiva de Ricoeur, pensamos que la ciudad ausente en este caso, tiene que ver más con un proceso de encriptación o endogamia en la posición de sujeto, ya que se concentra hacia el interior de la desaparición en un esfuerzo por poder mirar, no para buscar respuestas de la desaparición en un esfuerzo por poder mirar, no para buscar respuestas de 28) y así intentar recomponer y referir la imagen de la violencia:

urdir la forma en el género

pegar partes tocar cuerpos

plegar hundiendo agujas sellando

el futuro del cuerpo su disfraz inútil

esa copia de la memoria primera

que anade y recorta tras el brillo

el zumzum de las hojas abriendo 


\section{bordes}

tajeando ranuras por donde mirar (45).

El silenciar que nos propone Descomposición no es un mecanismo de poder que reclama olvido e impunidad como, conocemos, sería y es en los contextos de terrorismo de Estado, sino que se trataría de una estrategia de resistencia y autocuidado. Corresponde a la voluntad de no narrar para resguardar las huellas de los muertos y desaparecidos en espacios inaccesibles para el poder hegemónico con el propósito de proteger un discurso y las subjetividades que en él se construyen. Podríamos, quizás, hablar de la ciudad en Liliana Lukin como una memoria reservada (Acevedo, 2012), una ciudad que no es exteriorizada y que inviste una representación de silencio implícito. Su "clandestinidad" puede proyectarse a otro momento -como lo hacen muchas escrituras de los años 90-, o como un suplemento que se manifiesta en la dislocación silenciosa de la mirada de la sujeto y que solo nos llega por un rabillo fugaz en el intento de reconstruir conocimiento. Es así como esta memoria voluntaria de la ausencia o del silencio se sitúa entre las fronteras de un olvido figurado y la subversión. Hay que poner atención entonces a las rupturas que se encuentran en los sentidos textuales que la poeta construye, ya que no solo existen rompimientos en el lenguaje para hacer, de cierta forma, ininteligible la experiencia de lo vivido para las redes de control militar, sino que también hay fracturas tácitas con el espacio como simbólica de un tipo de violencia que sepulta los intercambios sociales no solo de subjetividades, sino que culturales, políticos, etarios y de género, solo por nombrar algunos.

Aquí entra en juego la noción de representación como una significación que es claramente problemática porque siempre trae consigo una zona de irrepresentabilidad; es la promesa de una revelación que no se produce (Monder, 2010:91). La omisión o el silencio como estrategia de resistencia son modos de manifestar o significar un intransmisible del horror a partir de una estética del silencio en oposición a una política del silenciamiento impuesta por los sistemas de represión, dado que esta decisión por el "silencio" nunca es completa, siempre es fragmentaria, puesto que se trata de una forma de construir lenguaje y que tiene que ver con realizar un recorte a la catástrofe. El silencio como la posibilidad ante la crisis del lenguaje en la literatura de los 80 en Argentina -y en Chile también-, pasa a tomar un papel determinante; al mismo tiempo que opone resistencia al lenguaje, lo desafía en sus propios límites.

El silencio se impone así como reverso y contracara de la representación de la desaparición forzada de personas y que la autora presenta como re sistencia al olvido y como el acceso al conocimiento de la interrogante ¿que sucedió? Solo los cuerpos desaparecidos, ausentes, contienen la respuesta, la que ha sido vedada por el régimen del terror, justamente porque el cuerpo torturado-desaparecido se constituye en la prueba que testifica el crimen. Se oculta entonces la prueba y los asesinos quedan en la impunidad ${ }^{10}$. De

10 Durante las dictaduras en el Cono Sur se aplicaron las "técnicas de desaparecimiento" que consistían "básicamente, primero [en] aterrorizar y después destruir al enemigo. Esa 
este modo, si no hay cuerpo en Descomposición, no hay nada, todo ha desparecido, incluyendo el lenguaje porque, indudablemente, forma parte de lo desintegrado por la violencia:
alguien habla a un auditorio
donde las cabezas que no están devoran
el único lugar vacío: balbuceos
de un idioma que no por conocido
es menos sucio en los bordes está muerto
la luz pega en las cosas no deja ver
aunque nada parezca para ser mirado
y huela a semen y avancen ciertas palabras
sobre otras

y nosotros y nosotros la luz pega en los ojos (33).

Solo queda, podríamos decir, la mirada enloquecida y cegada por la crueldad de una sujeto que, aún así, busca para recomponer, por medio de costuras, los cuerpos fantasmas, cuerpos muertos que aparecen para empujar retazos de memoria. La identificación con la ausencia, sin embargo, trae un sonido, un balbuceo porque "el silencio continúa siendo, inevitablemente, una forma del lenguaje (en muchos casos, de protesta o acusación) y un elemento del diálogo" (Sontag, 2005). En este sentido, pensamos que el silencio aparece en el lugar de aquello que no puede aparecer o representar. En el poemario, el silencio o la desaparición emerge como ruina y se posiciona de manera contigua a la ausencia de una ciudad.

El eje del libro es la problemática de la representación de la desaparición forzada de personas como consecuencia de la sistematización de la violencia. La desaparición es la disolución física y por otra parte también desaparece el espacio en favor de la denuncia, porque el horror va desalojando el propio hecho de vivir y habitar. La violencia es la amenaza de la anulación del cuerpo y con él, la ciudad. Solo que en Descomposición, la ciudad está silente y el cuerpo-muerto-torturado regresa para que la sujeto y el colectivo produzcan memoria para la resistencia y el conocimiento de los hechos. Por lo mismo, Liliana Lukin plantea la terrible pérdida del cuerpo y el hábitat propios a modo de correlato de la imposición del silenciamiento para la impunidad, es decir, el cuerpo y el espacio apropiados y cerrados en beneficio del dictador. Es la pérdida de las relaciones e intercambios humanos.

Los trayectos humanos, en el poemario, han sido reemplazados por apariciones de subjetividades y cuerpos vulnerados hasta más allá de cualquier límite, rompiendo (desapareciendo) todo lo que se necesita para construir vida. Esto sería el ultraje disolutorio, el itinerario catastrófico que tuvo que

es la técnica del desaparecimiento. No hay muertos. Se detiene a un dirigente subversivo y se le desaparece. Con esto se aterroriza y el resto de los miembros de su célula quedan destruidos [...] quedan aterrorizados y eso lo destruye no solo [a él] sino [que a su] familia, sus amigos, a los conocidos. Por eso este tipo de guerra es efectiva, porque con uno que desaparezcas destruyes a un radio muy grande de enemigos". Entrevista realizada por Nancy Guzmán al hijo de Manuel Contreras, Manuel Contreras V. Nancy Guzmán Jasmen. Ingrid Olderock. La mujer de los perros. Santiago: Ceibo ediciones, 2014, p. 48. 
mantener la ciudad bajo dictadura, ya que "la ciudad es la mayor forma política de la historia" (Virilio, 1999 citado en Pirela, 2001:105) y por lo mismo, se le silenció.

Es así como Liliana Lukin nos propone, por medio de la supresión o cancelación del espacio urbano, el fracaso político de la ciudad, representado en la desaparición violenta de las subjetividades corporales que le dan ese sentido político a la ciudad. Estamos ante la representación de una tragedia que interroga, en su ausencia, acerca de si subsiste una representación posible cuando se extravía el lugar. El texto responde a esta interrogante, justamente, a partir de la descomposición de los cuerpos y el lenguaje en cuanto, este último, se complejiza en una desarticulación de aparentes sinsentidos que le rehúyen al establecimiento de un lugar físico determinado.

Así entonces, en el poemario la desaparición de lo material, de lo viviente, señala la dificultad inmediata de no poder reanudar la travesía del intercambio humano Se trata de la imposibilidad de restablecer el espacio de la convivencia común, de retornar a la vida política, es decir, a la ciudad.

\section{Comentarios finales}

Sin duda que tanto Pena corporal como Descomposición y como otras producciones literarias de la época, se construyen en general como discursos estéticos y políticos, cuyo cometido fundamental es comunicar. Ambas poetas construyen sus libros como depositarios de una experiencia inmediata, la que se transforma en sentidos significativos en la construcción posterior de la memoria. Se componen como memorias complejas forjadas por contextos de terror vigentes a la escritura de los libros, como también por procesos subjetivos en los cuales lo "relatado" se acompaña de alcances terribles y traumáticos representados por un lenguaje complejo que da cuenta de sujetos, tiempos y espacios dañados.

De acuerdo con lo que nos planteamos para la lectura del poemario revisado, podemos apuntar que tanto Pena corporal como Descomposición se configuran como discursividades que, de diferentes modos, postulan una representación de la violencia ejercida por el terrorismo de Estado en Chile y Argentina durante las últimas dictaduras. En términos generales, ambos textos refieren el gran atentado que operó en contra de las relaciones, el contacto, los cuerpos y las subjetividades. Sabemos que si se destruyen estas dimensiones de lo humano, se destruye también el territorio donde se movilizan dichas dimensiones. Lo mismo pasa con el habla y el lenguaje, en el sentido de que la privación violenta de la palabra es privarse de los demás y del espacio común que se comparte cultural y socialmente.

Si bien el tratamiento de la problemática del silencio es trabajado de diferentes modos en cada uno de los libros, no deja de posicionarse como la interrupción crítica para quien lee en cuanto es un llamado a persistir en la necesidad de reubicar el cuerpo con relación al territorio, el cuerpo en relación con los demás. No solo el cuerpo humano, sino que también el cuerpo social y el cuerpo territorial. El silencio y la ciudad emergen como pulsiones fundamentales dentro de una doble mirada. En el texto de Liliana Lukin, la 
elipsis nada tiene que ver con el olvido y menos con la tensión entre este mismo y el recuerdo, sino que es una problemática del no decir que pone en escena el conflicto de la representación de lo terrible de la violencia política bajo regímenes de opresión. La representación entonces se hace compleja porque a la postre nos lleva a la pregunta de cómo significar en el lenguaje la problemática del sufrimiento, de la tortura y de la desaparición, por ejemplo. Por lo mismo, la utilización del lenguaje y del silencio se presenta como una intervención lingüística, debido a que no se puede alcanzar directamente la violencia, lo que no quiere decir que exista un tomar distancia, sino que es la imagen de una problemática que tiene que ver con la crisis de la identidad, con la representación del espanto para dar cuenta del parentesco con la realidad. Entonces, se trata de una disputa poética que de igual forma es una disputa ética. Por su parte, Elvira Hernández acude al silencio impuesto, es decir, al silenciamiento como mecanismo de ocultación de pruebas y de blanqueamiento del asesinato sistemático. Por lo que hablamos de la denuncia de una omisión intencionada, la que tiene como fin la instalación de una memoria oficial que directamente se relaciona con la construcción de la mentira histórica.

La tensión que emerge entre ambos textos o si se quiere el escenario dialógico que intercambian los dos poemarios en relación con la presenciaausencia devastadora del cuerpo de la ciudad, transita entre la vejación terrible y la supresión por desaparición de cualquier posibilidad de habitar el terror. Por lo mismo, se construyen como discursos que aportan a la discusión ética acerca de los consecuencias reales y posibles de la representación de la violencia, el salvajismo y la catástrofe, y nos advierten sobre la posibilidad de tratar lo inefable y de llevar al reconocimiento del daño causado en diferentes dimensiones de lo vital, como la identidad, la subjetividad, los trayectos sociales y los espacios que permiten el intercambio de todas estas dimensiones y otras más.

Para terminar, por ahora queda por decir que ante la imposición de un orden absoluto, estas propuestas escriturales de mujeres plantean la paradoja de la afirmación del dictador. Hablamos de afirmación a partir de la sospecha de que a través del sujeto, ya sea represor o reprimido, torturador o torturado, asesino o asesinado, aparece la figura del dictador. Estos "excesos" en la escritura resultan de un ejercicio de fragmentación del sujeto en muchos niveles, dando cuenta, en un primer orden, de un amplio conocimiento entregado por la experiencia presencial de la cultura del terror, para luego certificarla, resistirla y rechazarla. Por lo mismo además forman parte de campo en construcción de las "narrativas" de la violencia y por consecuencia, de los trabajos de la memoria.

\section{Obras citadas}

Acevedo, Óscar. Agonistas, sub/alternas y reservada: memorias de las víctimas. Tesis para optar al grado de Maestría en Estudios Culturales. Facultad de Ciencias Sociales, Universidad Javeriana, Bogotá, Colombia, 2011. Disponible en http://repository.javeriana.edu.co/handle/10554/800

Brito, Eugenia. Campos minados. Santiago: Cuarto Propio, 1994.

Dalmaroni, Miguel. La palabra justa: Literatura, critica y memoria en la Argentina, 1960-2002. Chile, Editorial Melusina / RIL Editores, 2004. 
Guzmán Jasmen, Nancy. Ingrid Olderock. La mujer de los perros. Santiago: Ceibo ediciones, 2014.

Hernández, Elvira. Pena corporal (inédito).

Jelin, Elizabeth. Los trabajos de la memoria. España y Argentina: Siglo XXI Editores, 2002.

_. y Longoni, Ana (comp.). Escrituras, imágenes y escenarios ante la represión. España y Argentina: Siglo XXI Editores, 2005.

Lukin, Liliana. Descomposición. Argentina: Ediçiones de la Flor, 1986.

Martínez Estrada, Ezequiel. Lírica social amarga. Últimos escritos sobre ajedrez, ciudad, técnica, paradoja. Logroño: Editorial Pepitas de Calabaza, 2003.

Monder, Samuel. "Zona de silencio: discursos críticos y políticas de la representación" en revista Taller de Letras, no 47, 2010, pp. 89-94.

Monteleone, Jorge. "Conjura contra la lengua culpable: relato y poesía" en revista Milpalabras no 5, 2003, pp. 27-32.

Nómez, Naín. "La poesía chilena. Representaciones del terror y fragmentación del sujeto en los primeros años de dictadura" en Acta Literaria n० 36 , 2008, pp. 87-101.

Pirela Torres, Alexis. "La estética de la desaparición y la ciudad en Paul Virilo" en Notas y debates de la actualidad. Utopía y praxis latinoamericanas, año 6 , no 15, 2001, pp. 100-107.

Richard, Nelly. Lo político y lo crítico en el arte. Artistas mujeres bajo dictadura en Chile. Valencia: IVAM Institut Valencia d'Art, 2011.

Sarlo, Betariz. La ciudad vista. Buenos Aires: Siglo XXI Editores, 2009.

Sepúlveda, Magda. "Santiago, patipelá y empielá: la feminización de la ciudad dictatorial" en Sonia Montecinos (comp.). Mujeres chilenas: fragmentos de una historia. Santiago: Catalonia, 2008.

Ricoeur, Paul. La lectura del tiempo pasado: memoria y olvido. España: Universidad Autónoma de Madris, 1999.

Viñar, Maren y Marcelo. Fracturas de memoria. Crónicas para una memoria por venir. Montevideo: Ediciones Trilce, 1993. 
